\title{
Coating on Magnesium Alloy with Super Duralumin by Hot Extrusion and Evaluation of Its Surface Properties ${ }^{* 1}$
}

\author{
Toko Tokunaga $^{1}$, Kazushi Sotomoto ${ }^{2, * 2}$, Munekazu Ohno ${ }^{1}$ and Kiyotaka Matsuura ${ }^{1}$ \\ ${ }^{1}$ Faculty of Engineering, Hokkaido University, Sapporo 060-8628, Japan \\ ${ }^{2}$ Graduate School of Engineering, Hokkaido University, Sapporo 060-8628, Japan
}

\begin{abstract}
The poor corrosion resistance of Mg alloys, which is well known as one of the lightest structural metal materials, limits a wide use of these alloys. In order to dramatically increase not only the corrosion resistance but also the surface hardness of Mg alloys (AZ80), coating with A2024 Al alloy by hot extrusion has been attempted in this study. The coating was successfully realized by hot extrusion of a Mg alloy (AZ80) billet together with an Al alloy plate placed between the billet and the extrusion die. The A2024 Al alloy-coated Mg alloy exhibited an excellent corrosion resistance and no weight loss was observed after immersion in a 5 mass $\% \mathrm{HCl}$ aqueous solution for 10 min while a weight loss of about $1500 \mathrm{~g} \cdot \mathrm{m}^{-2}$ was observed in case of AZ80 Mg alloy without coating under the same condition. The surface hardness of the coated alloy was increased to about $85 \mathrm{HV}$ by aging for $144 \mathrm{~h}$ at room temperature after solution treatment for $3 \mathrm{~h}$ at $673 \mathrm{~K}$. [doi:10.2320/matertrans.M2017317]
\end{abstract}

(Received October 24, 2017; Accepted December 19, 2017; Published February 2, 2018)

Keywords: magnesium alloy, A2024 aluminium alloy, coating, extrusion, aging treatment, hardness, corrosion resistance

\section{Introduction}

$\mathrm{Mg}$ alloys are characterized by the lowest density among all the practical structural metals, and also by their high strength-to-weight ratio. Moreover, they have good recyclability and electromagnetic shielding ability ${ }^{1)}$. Recently, as a solution to the environmental problems such as air pollution and global warming, improvements in fuel efficiency by weight saving of automobiles and air crafts have been attempted. One of the weight-saving strategies is replacement of steel with light metals, i.e., Al alloys, and further weight-saving is expected by replacement with $\mathrm{Mg}$ alloys ${ }^{1)}$. However, the application of $\mathrm{Mg}$ alloys is still limited because of the poor corrosion resistance of $\mathrm{Mg}$ alloys.

In order to improve the corrosion resistance, the present authors have recently developed a simple method to coat $\mathrm{Mg}$ alloys with $\mathrm{Al}$ by using a hot extrusion process, and demonstrated that the pure Al-coated AZ80 Mg alloy exhibits a good corrosion resistance even in an aqueous solution of $\mathrm{HCl} \mathrm{acid}^{2}$. In addition, the Al-coated $\mathrm{Mg}$ alloy exhibited better strength and elongation than the conventional $\mathrm{Mg}$ alloys because of the grain refinement due to recrystallization during and after the extrusion. Moreover, the Al-coated $\mathrm{Mg}$ alloy was successfully hot-rolled without breaking or debonding of the Al coating layer, and the rolled sheet exhibited a superplastic elongation of $710 \%$. This superior formability of the Al-coated $\mathrm{Mg}$ alloy is very useful for the production of the parts having extremely complex shapes. However, in the previous study on the Al-coated $\mathrm{Mg}$ alloy ${ }^{2}$, pure Al was used as a coating material, which is soft and easily scratched, and it involves a risk of impairment in corrosion resistance when the coating is severely damaged. For the solution of such a problem, it will be useful to employ a high strength $\mathrm{Al}$ alloy instead of pure $\mathrm{Al}$. In the present study, the possibility of the use of a super duralumin A2024

\footnotetext{
${ }^{* 1}$ This Paper was Originally Published in Japanese in J. Japan Inst. Met. Mater. 81 (2017) 389-393

${ }^{* 2}$ Graduate Student, Hokkaido University
}

$\mathrm{Al}$ alloy is investigated, which possesses superior hardness and tensile strength, and the corrosion resistance and surface hardness of the A2024-coated AZ80 Mg alloy are investigated.

\section{Experimental}

\subsection{Composite fabrication}

The hot extrusion process was used to coat the A2024 Al alloy on $\mathrm{Mg}$ alloy substrate. The detail of the process can be found in the authors' previous study ${ }^{2)}$. The AZ80A-T5 Mg alloy commercial rod (Mg-8.2Al-0.6Zn-0.4Mn (mass\%)), having a diameter of $42 \mathrm{~mm}$ was used. The rod was cut into a cylinder of $30 \mathrm{~mm}$ in thickness, and it was press-formed to the substrate with a rectangular cross section of $40 \mathrm{~mm} \times$ $40 \mathrm{~mm}$. The substrate was solution-treated at $673 \mathrm{~K}$ for 5 hours and then aging-treated at $623 \mathrm{~K}$ for 1 hour. On the other hand, a commercial rectangular bar of A2024P-T351 $\mathrm{Al}$ alloy (Al-4.4Cu-1.4Mg-0.6Mn (mass $\%)$ ), having a cross section of $40 \mathrm{~mm} \times 42 \mathrm{~mm}$, was used for the coating material. The Al alloy bar was cut into a plate with a thickness of $7 \mathrm{~mm}$ and cross section of $40 \mathrm{~mm} \times 40 \mathrm{~mm}$.

The metals were put in an extrusion container, preheated up to $603 \mathrm{~K}$ in an electric furnace, in the order of the Mg alloy substrate and the $\mathrm{Al}$ alloy plate. The die was put on the Al plate, and the hot indirect extrusion was conducted by pressing the rams on the die downward. At the first trial, coating failed, since the extruded bar was only partially covered with the Al alloy coating. It was considered that the failure was due to a very high deformation resistance of the A2024 alloy at the extrusion temperature compared with that of the AZ80 alloy. In order to soften the A2024 alloy, the A2024 alloy was annealed at $683 \mathrm{~K}$ for 3 hours prior to the extrusion to remove the fine precipitates. After the extrusion, the alloy can be hardened by additional solution and aging treatments. The detailed explanation of the solution and aging treatments will be given in the next section.

Figure 1 shows the shape and dimensions of the die used in the present study. A die angle of $20^{\circ}$ was chosen based on 
(a)

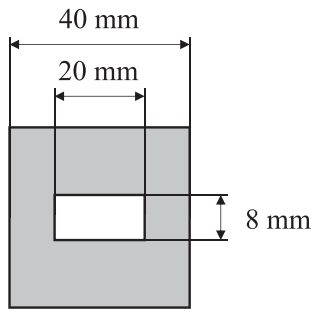

(b)

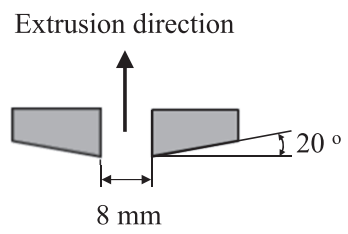

Fig. 1 Schematic images of a die used in the present study: (a) overhead view and (b) cross-section of the die.

the results of the authors' previous study ${ }^{2)}$, where the effect of the die angle on the uniformity of the coating layer was investigated and it was found that the thickness was most uniform when the die angle was $20^{\circ}$. The AZ80 alloy substrate and the A2024 alloy plate were put in the container and heated up to $643 \mathrm{~K}$ in 30 minutes, and they were indirectly extruded at a ram speed of $8.0 \mathrm{~mm} / \mathrm{min}$ and at an extrusion ratio of $87.5 \%$. The microstructure of the extruded composite was observed by optical microscope and Scanning Electron Microscopy (SEM). The concentration profiles of the elements were obtained across the A2024/ AZ80 interface by Field Emission-Electron Probe Micro Analyzer (FE-EPMA).

The change in thickness of the A2024 alloy coating layer along the extrusion direction was investigated. The extruded bar was cut at every $10 \mathrm{~mm}$ from the tip, and on each cross section, the thickness of the coating layer was measured along 12 different lines perpendicular to the extrusion direction and the average was recorded as a thickness of the coating layer on the cross section.

\subsection{Heat treatment of the composite}

The heat treatment in this study includes solution and aging treatments, and their conditions are summarized in Table 1. Although the solution treatment is usually performed at approximately $773 \mathrm{~K}$ for A2024 alloy ${ }^{3-5)}$, $673 \mathrm{~K}$ was chosen in this study to avoid the melting of the intermetallic compounds formed at the $\mathrm{Al} / \mathrm{Mg}$ interface such as $\mathrm{Al}_{3} \mathrm{Mg}_{2}$ and $\mathrm{Al}_{12} \mathrm{Mg}_{17}$, the melting temperatures of which are 723 and $733 \mathrm{~K}$, respectively ${ }^{6}$. The composite was held at $673 \mathrm{~K}$ for 2 or 3 hours and then water-quenched. Following the solution treatment, an artificial or a natural aging was performed at $453 \mathrm{~K}$ for 0 to 10 hours and at room temperature for 0 to 144 hours, respectively. After the artificial aging treatment, the samples were furnace-cooled to room temperature.

\subsection{Characteristics investigation}

Corrosion resistance of the composite was evaluated by monitoring the weight loss during the immersion in a 5.0 mass $\% \mathrm{HCl}$ aqueous solution at room temperature. In addition to the corrosion test of the as-extruded composite, the as-received AZ80 Mg alloy and A2024 Al alloy were also corrosion-tested for a comparison purpose. In order to focus on the same area in the corrosion test for all the samples, the surface of each sample was covered by epoxybased adhesive, leaving a non-covered square window of $10 \mathrm{~mm} \times 10 \mathrm{~mm}$.
Table 1 Heat treatment conditions.

\begin{tabular}{|c|c|c|c|}
\hline \multicolumn{2}{|c|}{ Solution treatment } & \multicolumn{2}{|l|}{ Aging treatment } \\
\hline Temp. (K) & Holding time $(\mathrm{h})$ & Temp. (K) & Holding time $(\mathrm{h})$ \\
\hline \multirow{24}{*}{673} & \multirow{12}{*}{2} & no aging & \\
\hline & & \multirow{6}{*}{ Room temperature } & 24 \\
\hline & & & 48 \\
\hline & & & 72 \\
\hline & & & 96 \\
\hline & & & 120 \\
\hline & & & 144 \\
\hline & & & 2 \\
\hline & & & 4 \\
\hline & & 453 & 6 \\
\hline & & & 8 \\
\hline & & & 10 \\
\hline & \multirow{12}{*}{3} & no aging & \\
\hline & & \multirow{6}{*}{ Room temperature } & 24 \\
\hline & & & 48 \\
\hline & & & 72 \\
\hline & & & 96 \\
\hline & & & 120 \\
\hline & & & 144 \\
\hline & & \multirow{5}{*}{453} & 2 \\
\hline & & & 4 \\
\hline & & & 6 \\
\hline & & & 8 \\
\hline & & & 10 \\
\hline
\end{tabular}

The surface hardness was measured by using a Vickers Hardness tester. The applied load and the holding time were set at $500 \mathrm{~g}$ and 30 seconds, respectively. The testing was performed at 24 different points in each sample, and the maximum and the minimum values and the second maximum and the second minimum were removed when the average value was calculated. The hardness of the A2024 alloy coating layer was measured after the extrusion and also after the heat treatment shown in Table 1, and the effects of the solution and aging treatments on the hardness were investigated. Moreover, the hardness of the AZ80 alloy substrate was also measured. The applied load and the holding time were $100 \mathrm{~g}$ and 30 seconds for the AZ80 alloy substrate.

\section{Results and Discussion}

\subsection{Microstructure and the coating thickness}

Figures 2 (a) and (b) illustrate the overview of the extruded bar and its cross-section, respectively. The extruded bar is soundly coated by A2024 Al alloy on the whole surface. In Fig. 2 (b), no debonding or cracking can be seen at the A2024/AZ80 interface. The enlargement of the interface is shown in Fig. 3 (a). Between the A2024 alloy and the AZ80 alloy, a granular phase with a diameter of about $0.5 \mu \mathrm{m}$, a plate-like phase with a thickness of about $3 \mu \mathrm{m}$ and a saw-like phase with a thickness of about $1 \mu \mathrm{m}$ are observed from the A2024 alloy side to the AZ80 alloy side. Although a void of about $0.3 \mu \mathrm{m}$ in a diameter can be seen near the center of Fig. 3 (a), formation of the above- 
mentioned phases indicates the occurrence of sufficient interdiffusion of $\mathrm{Al}$ and $\mathrm{Mg}$ across the bonding interface which results in a strong bonding between the A2024 and AZ80 alloys. In order to identify these phases, composition analysis was conducted by using the FE-EPMA on the A-A' line shown in Fig. 3 (a). The results are shown in Fig. 3 (b). Since the atomic composition of the above-mentioned three phases were detected as $65 \mathrm{Al}-5 \mathrm{Cu}-30 \mathrm{Mg}, 60 \mathrm{Al}-40 \mathrm{Mg}$ and $35 \mathrm{Al}-65 \mathrm{Mg}$, those phases can be considered as $\mathrm{Al}_{6} \mathrm{CuMg}_{4}$, $\mathrm{Al}_{3} \mathrm{Mg}_{2}$, and $\mathrm{Al}_{12} \mathrm{Mg}_{17}$, respectively, based on the phase diagram shown in Fig. 4.

Figure 5 shows the thickness change of the coating layer with respect to the distance in the extrusion direction. At the initial stage of the extrusion, the $\mathrm{Al}$ alloy plate near the die hole did not undergo severe plastic deformation, and thus the coating is very thick near the tip of the extruded bar. After the distance of around $50 \mathrm{~mm}$, the coating thickness was uniform at approximately $400 \mu \mathrm{m}$. The thickness of the coating layer was 200 to $300 \mu \mathrm{m}$ when AZ80 alloy was similarly coated with the pure $\mathrm{Al}$ using the $\mathrm{Al}$ plate of $3 \mathrm{~mm}$ in the initial thickness in the present authors' previous study ${ }^{2}$. The difference in coating thickness between the present and previous studies is considered to be due to the initial thickness of the coating material, since a sensitivity analysis has revealed that the initial thickness of the coating material strongly affects the coating thickness of the extruded clad bar $^{8)}$. However, it is also considered that the difference in the coating thickness is affected by the difference in the deform-

(a)

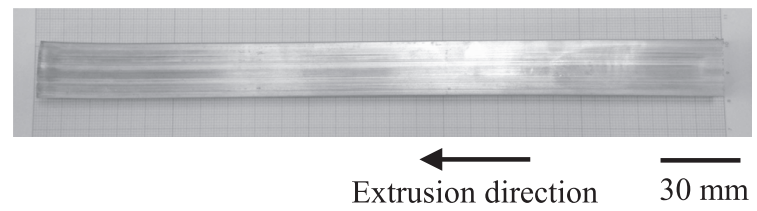

(b)

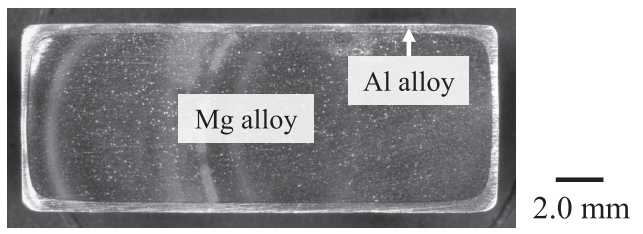

Fig. 2 (a) The overview of the extruded bar and (b) cross-sectional picture of the extruded bar. ability of the coating material.

\subsection{Corrosion resistance of the composite}

Figure 6 illustrates the weight loss behavior during the corrosion test where the samples were immersed in a 5.0 mass \% $\mathrm{HCl}$ aqueous solution. The results of AZ80 $\mathrm{Mg}$ alloy and A2024 Al alloy are also shown for comparison.

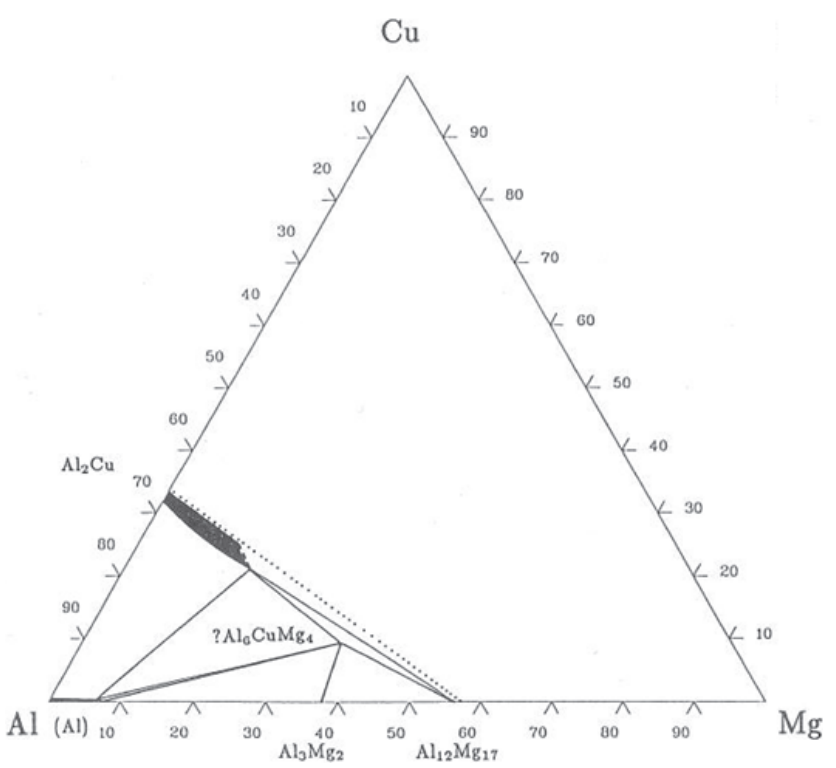

Fig. 4 Al-Cu-Mg ternary phase diagram at $298 \mathrm{~K}^{7)}$.

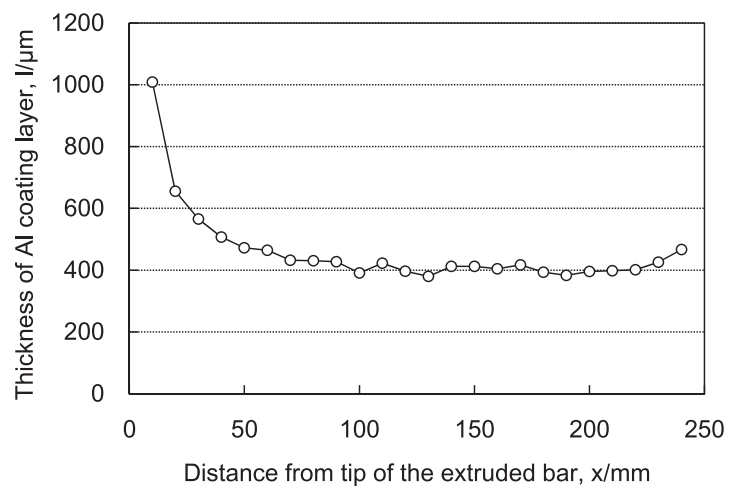

Fig. 5 Thickness change of A2024 Al alloy coating layer with respect to the distance from tip of the extruded bar.
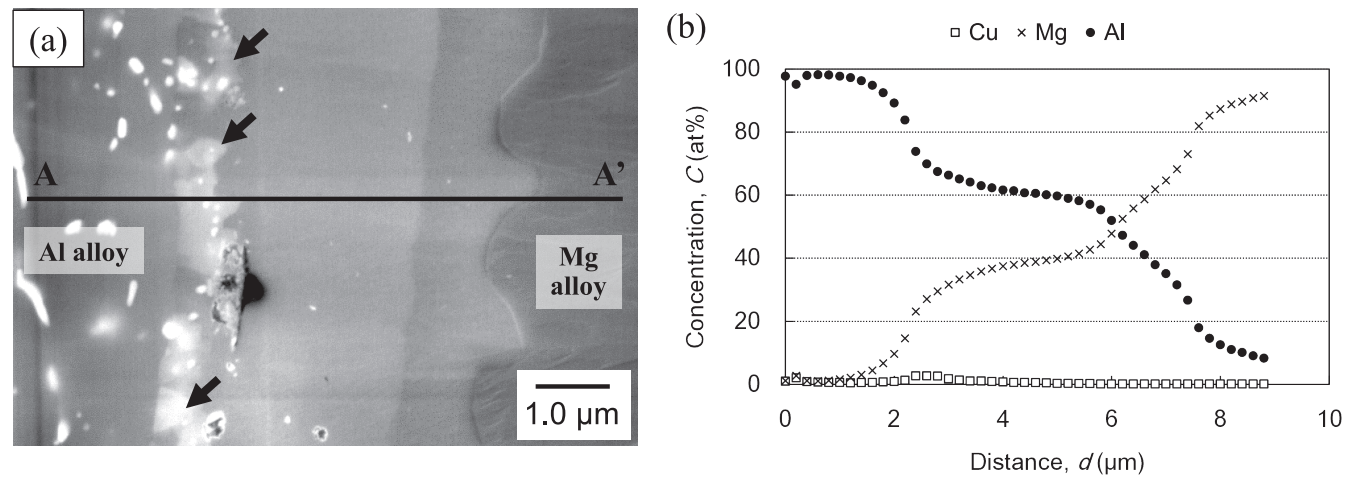

Fig. 3 (a) SEM image of $\mathrm{Al} / \mathrm{Mg}$ interface after extrusion, and (b) EPMA results obtained from the line A-A' shown in (a). 
The bare AZ80 alloy severely reacted with the $\mathrm{HCl}$ aqueous solution to form a lot of small bubbles from the beginning of the immersion. On the other hand, the A2024 alloy and the as-extruded composite did not react at all, and no weight loss was observed. Thus, the present composite exhibited a good corrosion resistance of the same level as the A2024 alloy. A slight weight gain is observed for the A2024 alloy and the as-extruded composite, the reason for which may be due to imperfect drying of the epoxy-based adhesive using for the masking of the samples. The same weight gain should have occurred in the AZ80 alloy sample, however, the weight gain was negligibly small compared with the significantly large weight loss.

\subsection{Surface hardness of the composite}

Due to the annealing before the extrusion, the hardness of the A2024 alloy plate significantly decreased from 120 with a standard deviation of 6.9 to 53 with a standard deviation of 1.8. After extrusion, the hardness of the A2024 alloy slightly increased to 60 with a standard deviation of 1.1. The extrusion led an increase in hardness of the A2024 alloy. The

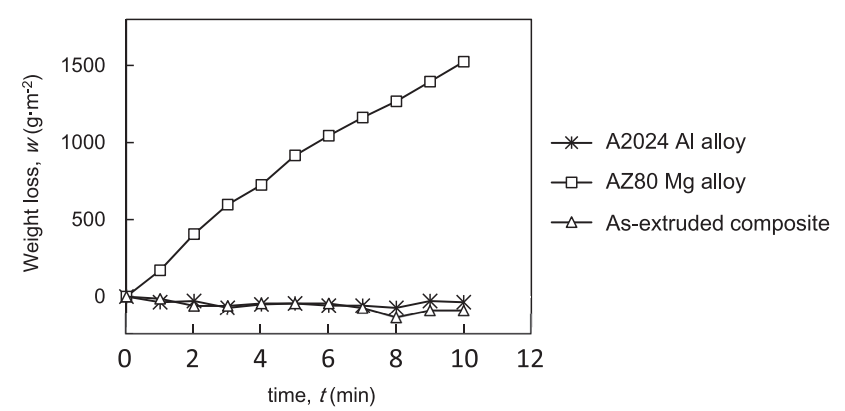

Fig. 6 Weight loss behavior of the A2024 Al alloy, AZ80 Mg alloy and the as-extruded composite immersed in 5.0 mass $\% \mathrm{HCl}$ aqueous solution at room temperature. hardness of the AZ80 alloy also increased to a small extent by the extrusion, which was 60 and 64 with standard deviations of 2.5 and 2.2 before and after the extrusion, respectively.

The coating layer was softer than the substrate just after the extrusion, which is against with the present purpose, i.e., coating of $\mathrm{Mg}$ alloy with a hard $\mathrm{Al}$ alloy. In order to increase the hardness of the coating layer, a variety of heat treatments listed in Table 1 were performed. The effect of the heat treatment on the hardness was investigated by the Vickers hardness test, and the optimal condition of heat treatment was studied.

Figures 7 (a) and (b) illustrate the results of hardness test after solution treatment followed by the artificial aging at $453 \mathrm{~K}$ or natural aging at room temperature. The error bar on each plot indicates the standard deviation. In the solutiontreated composite, before the aging treatment, the hardness of the A2024 alloy coating layer was 62 irrespective of the solution treatment time of 2 or 3 hours. Also, in those samples, remarkable difference in the standard deviation was not observed, and the standard deviations were 0.8 and 1.3 , respectively. All the solution-treated samples before aging treatment (shown as symbol $\times$ and $\bigcirc$ in Fig. 7) show slight increase in hardness compared to the as-extruded sample (shown as symbol in Fig. 7).

Aging treatment significantly contributes to the increment in hardness of the A2024 alloy coating layer. The A2024 alloy coating layer, which was solution-treated at $673 \mathrm{~K}$ for 3 hours followed by the aging treatment at $453 \mathrm{~K}$ for 4 hours, shows the maximum hardness of 77 with a standard deviation of 1.2. After showing the maximum hardness, viz. more than 4 hours of aging time, the hardness gradually decreases. This decrement can be considered as a result of overaging, associated with a coarsening of hardening precipitates. On the other hand, the hardness of the A2024 alloy coating layer subjected to the natural aging treatment (Fig. 7 (b)) in- (a)

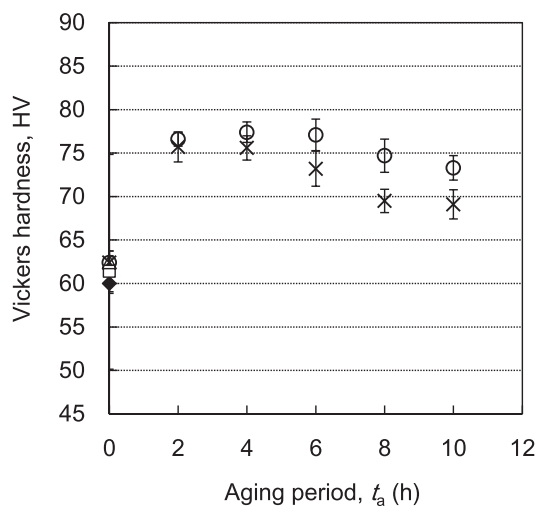

(b)

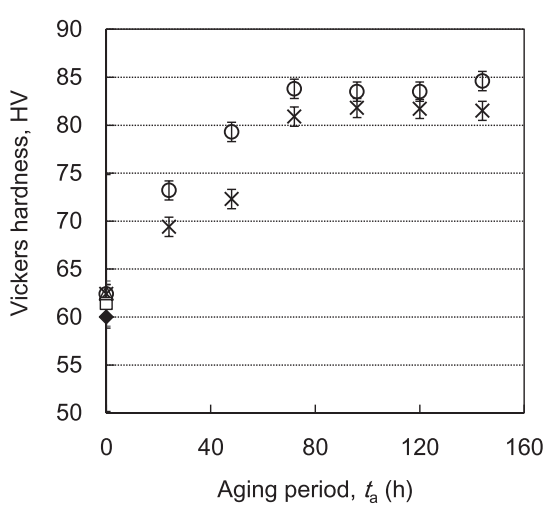

- As-extruded

$\times$ A2024 Al coating layer, solution-treated for $2 \mathrm{~h}$

○ A2024 Al coating layer, solution-treated for $3 \mathrm{~h}$

$\square \quad A Z 80 \mathrm{Mg}$ alloy substrate, solution-treated for $2 \mathrm{~h}$

$\triangle \mathrm{AZ} 80 \mathrm{Mg}$ alloy substrate, solution-treated for $3 \mathrm{~h}$

Fig. 7 Vickers hardness test results obtained from composite after solution treatment and (a) artificial aging at $453 \mathrm{~K}$ and (b) natural aging at $298 \mathrm{~K}$. The solution treatment was performed at $673 \mathrm{~K}$. 
creases as the aging time increases, and it remains constant after 72 hours. The maximum hardness of 85 was obtained from the sample solution-treated at $673 \mathrm{~K}$ for 3 hours followed by natural aging treatment for 144 hours. The standard deviation was 0.77 . The hardness of the coating layer measured in 3 weeks after the solution treatment was 83 with a standard deviation of 0.87 , which indicates that no significant change in hardness occurs after showing the maximum hardness. In any aging condition, the coating layer exhibited higher hardness than the Mg alloy substrate.

As for the A2024 alloy coating layer in both composites subjected to the artificial and the natural aging, the hardness was higher when the solution treatment time was longer. The increase in solution treatment time leads to the increase in concentration of the solute elements in the Al matrix phase closer to the solubility limit, and consequently, it leads to the increase in the amount of the precipitation after the aging treatment.

The hardness of the AZ80 alloy substrate in the composite solution-treated for 2 and 3 hours are also shown in Fig. 7 by symbols $\square$ and $\triangle$, respectively. The hardness of AZ80 alloy substrate was not changed significantly by the solution treatment at $673 \mathrm{~K}$. Generally, heating of $\mathrm{Mg}$ alloys causes deterioration in mechanical properties. However, in the present study, since the hardness of the $\mathrm{Mg}$ alloy did not decrease after heating to the solution treatment temperature, it is considered that the aging treatment at an appropriate low temperature gives no deterioration in mechanical properties. Consequently, the improvement in surface hardness of the A2024 alloy coating layer was succeeded by using the aging condition shown above without any hardness deterioration of the AZ80 alloy substrate. However, it should be noted that the hardness of 120 in the as-received A2024 alloy was not achieved in the A2024 alloy coating layer in the composite. The reason for this is discussed below.

As mentioned in section 2.2 , in the present study, the solution treatment temperature was set at $673 \mathrm{~K}$, which is approximately $100 \mathrm{~K}$ lower than a commonly employed solution treatment temperature of $773 \mathrm{~K}$. Although this low solution temperature was chosen to avoid melting of the intermetallic compound, it is known that this difference of $100 \mathrm{~K}$ in the solution treatment temperature is large enough to influence mechanical properties obtained by the subsequent aging treatment ${ }^{9)}$. This is why it was not possible to retrieve the hardness to the level of the as-received A2024 alloy.
By applying solution treatment for longer time than that in the present study, better solution of the alloying elements might be possible, and higher hardness could be obtained, although there may be a limit of hardening.

\section{Conclusions}

In order to improve the corrosion resistance and surface hardness of $\mathrm{Mg}$ alloys, coating on AZ80 Mg alloy with A2024 Al alloy, having superior corrosion resistance and high hardness, was attempted and the following conclusions were obtained.

(1) A2024 alloy-coated AZ80 alloy was successfully fabricated by hot extrusion, and it exhibited a good corrosion resistance.

(2) The hardness of the A2024 alloy coating layer increased and exceeded that of the AZ80 alloy substrate by applying the solution and aging treatments. A maximum hardness of $85 \mathrm{HV}$ was achieved by a solution treatment at $673 \mathrm{~K}$ for 3 hours and the natural aging at room temperature for 144 hours.

\section{Acknowledgements}

This work was partly supported by Nanotechnology Platform Program (Molecule and Material Synthesis) of the Ministry of Education, Culture, Sports, Science and Technology (MEXT), Japan.

\section{REFERENCES}

1) J.E. Gray and B. Luan: J. Alloy. Compd. 336 (2002) 88-113.

2) T. Tokunaga, K. Matsuura and M. Ohno: J. Jpn. Inst. Metals 75 (2011) 633-639.

3) D. Sun, X. Sun, D.O. Northwood and J.H. Sokolwski: Mater. Charact. 36 (1996) 83-92.

4) H. Kacar, E. Atik and C. Meric: J. Mater. Process. Technol. 142 (2003) $762-766$.

5) A. Meyveci, Í. Karacan, U. Çaligülü and H. Durmus: J. Alloy. Compd. 491 (2010) 278-283.

6) T.B. Massalski, H. Okamoto, P.R. Subramanian and L. Kacprzak: Binary Alloy Phase Diagrams, Second Edition Volume 1, (ASM International, 1990).

7) P. Villars, A. Prince and H. Okamoto: Handbook of Ternary Alloy Phase Diagrams, Volume 3, (ASM International, 1995).

8) T. Tokunaga, D. Szeliga, K. Matsuura, M. Ohno and M. Pietrzyk: Int. J. Adv. Manuf. Technol. 80 (2015) 507-513.

9) Y. Baba: JJILM 30 (1980) 520-533. 